\title{
A review of dental treatment of head and neck cancer patients, before, during and after radiotherapy: part 2
}

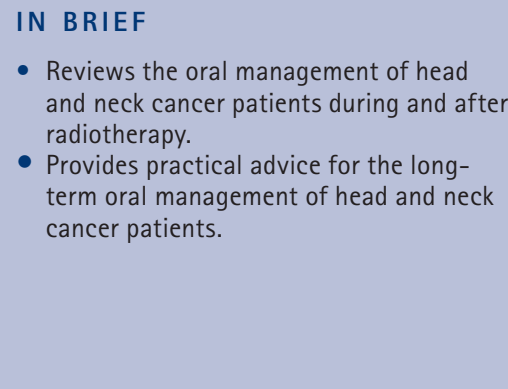

\author{
H. Jawad, ${ }^{* 1,2}$ N. A. Hodson ${ }^{3}$ and P. J. Nixon ${ }^{4}$
}

The incidence of head and neck cancer is on the rise. Radiation therapy is one of the major treatment modalities for the management of oral malignancies. As with any treatment modality, radiation therapy is associated with various complications. The second part of this series is a review of the oral changes that occur during and after radiotherapy and the oral management of head and neck oncology patients before, during and after radiotherapy. Dental practitioners will encounter patients who have been affected by cancer or who are current cancer patents. General dental practitioners (GDPs) have a vital and proactive role in supporting such patients. The aim of this article is to review the oral management of these patients during and after radiotherapy, and gives practical advice for GDPs and their teams in the long-term care of these patients.

\section{INTRODUCTION}

Patients undergoing radiotherapy require significant support from the dental team both during radiotherapy and once treatment is complete. Much of the advice can be provided by the patient's own general dental practitioner (GDP) in consultation with the restorative consultant on the oncology care team. Many patients with cancer will present to their GDP requiring routine dental care or advice and treatment for oral complications resulting from the malignancy and/or treatment modalities, including radiotherapy.

\section{THE ORAL MANAGEMENT OF ONCOLOGY PATIENTS DURING RADIOTHERAPY}

\section{Oral hygiene instruction}

Thorough oral hygiene is essential, especially during chemotherapy or radiotherapy treatment when the mouth is inflamed and sore. The best standard of oral hygiene is achieved by brushing, however, if this becomes too painful the use of a mouth wash is a good alternative. A chlorhexidine

'Oral and Maxillofacial Speciality Doctor, St Lukes Hospital, Bradford; ${ }^{2}$ Community Dental Officer, Shipley Health Centre; ${ }^{3}$ Senior Lecturer/Honorary Consultant in Restorative Dentistry, School of Medicine and Dentistry, UCLAN, ${ }^{4}$ Restorative Consultant, Leeds Dental Institute ${ }^{*}$ Correspondence to: Miss Huda Jawad

Email: H.jawad@nhs.net

\section{Refereed Paper}

Accepted 24 November 2014

DOI: $10.1038 /$ sj.bdj.2015.29

${ }^{\circledR}$ British Dental Journal 2015; 218: 69-74 gluconate mouth rinse at a concentration of $0.2 \%$ (Corsodyl) should be used three to four times daily ${ }^{1-3}$ and tooth brushing should be resumed at the earliest opportunity. ${ }^{4}$ When the mouth is too painful for cleaning and a mouthwash cannot be tolerated, the oral tissues should be swabbed with polygon oral swabs (Fig. 1; Rochaille Medical Limited, Cambridge, UK) or a gauze soaked in chlorhexidine three to four times daily. ${ }^{1}$ Polygon swabs are softer than cotton buds and cause less bleeding and pain when applied to the already inflamed mucosa. ${ }^{5}$

It should be noted that there is a Medical Device Alert with the use of oral swabs which recommends that it is important to check the foam head is firmly attached to the stick before use and not to leave the swabs soaking as this may affect the strength of the foam attachment. ${ }^{6}$

\section{Mucositis and pain relief}

A number of different interventions have been identified as providing some benefit, albeit weak, to prevent or reduce severity of mucositis. These include: aloe vera, amifostine, granulocyte-colony stimulating factor, intravenous glutamine, honey, keratinocyte growth factor, laser, polymixin/ tobramycin/amphotericin antibiotic pastille/ paste and sucralfate. ${ }^{7}$ There is some evidence that mucositis can be reduced by using ice chips (cryotherapy); $;^{7-9}$ however, clinically ice chips are difficult for most patients to tolerate.

Difflam (benzydamine hydrochloride) has been shown to give symptomatic relief in mild to moderate mucositis for some patients, particularly when used before meals. ${ }^{10} \mathrm{~A}$ 2\% lignocaine solution mouthwash will help when symptoms are more severe. ${ }^{11,12}$ Some authors have shown a chlorhexidine gluconate mouthwash can alleviate symptoms of mucositis, ${ }^{13}$ although a systematic review has found no benefit overall for its use in mucositis prevention. ${ }^{7}$

Paracetamol, particularly in the form of mucilage which coats the inflamed mucosa, can be useful in the early stages. The addition of codeine or dihydrocodeine can be useful as intermediate analgesics. Worsening symptoms are likely to require strong opiates such as morphine. ${ }^{14}$

The additional symptom of dysphagia has been reported to be relived with aspirinmucaine mouthwash, ideally used before meals. This should not be used for children under 12 years of age. ${ }^{15}$

\section{Oral candidal infections}

Patients who are post radiotherapy are more susceptible to oral candidiasis. When this is detected, ensuring optimum denture and oral

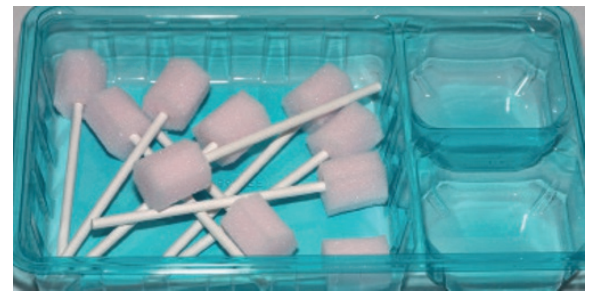

Fig. 1 Polygon swabs 
hygiene is the appropriate furst line measure. Persistent infection should be treated with antifungals. The use of nystatin and chlorhexidine simultaneously should be avoided as there is some evidence to suggest that both drugs inhibit each other's action; it is preferable to separate administration of these agents by at least one hour. ${ }^{16}$

Anti-fungal drugs that are absorbed or partially absorbed in the gastrointestinal tract, for example ketaconazole, have also been highlighted as an effective way of preventing the development of ${ }^{17}$ and treating oral candidiasis. ${ }^{18}$ Their use has to be balanced against the potential systemic side-effects.

\section{Xerostomia}

Patients initially develop the symptoms of xerostomia within a couple of weeks of starting radiotherapy and the dry mouth may not recover after the treatment has stopped. In general, this can be helped by frequent sips of cold water/milk or other sugar free nonacidic cool drinks. ${ }^{19}$ Frequent sips of water tend to be the most popular therapy with the majority of patients.

The use of saliva substitutes may be helpful to patients complaining of a dry mouth and offers symptomatic relief for patients with insufficient salivary function. There are a variety of preparations available including artificial saliva replacements (for example, gels, sprays and mouth rinses) or salivary stimulants (for example, chewing gums, citric acid tablets) (see Table 1). Properly balanced artificial saliva should be of a neutral $\mathrm{pH}$ and contain electrolytes (including fluoride) to correspond approximately to the composition of saliva. The acidic $\mathrm{pH}$ of some artificial saliva products may be inappropriate for dentate patients as these can cause dental erosion. Ideally, dentate patients should use a fluoride-containing preparation, as this may protect against caries. Additionally some preparations are derived from animal products and may be unsuitable for vegetarians and people from certain religious groups.

The British National Formulary states, that of the proprietary preparations, Aquoral ${ }^{\circledR}$, Biotène Oralbalance ${ }^{\circledR}$ gel or Xerotin ${ }^{\circledR}$ can be used for any condition giving rise to a dry mouth. BioXtra ${ }^{\circledR}$, Glandosane ${ }^{\circledR}$, Saliva Orthana ${ }^{\circledR}$, and Saliveze ${ }^{\circledR}$, have the Advisory Committee on Borderline Substances approval for dry mouth associated only with radiotherapy or sicca syndrome. Salivix ${ }^{\circledR}$ pastilles, which act locally as salivary stimulants, are also available for any condition leading to a dry mouth and saliva stimulating tablets may be prescribed for dry mouth in patients with salivary gland impairment (and patent salivary ducts). However, all of the available artificial saliva preparations may be purchased from a pharmacy.

Other suggested products include:

- Flavourless salad oil or dietary fat at night time lubricates the lips and tongue $^{20}$

- Sugarfree chewing gum stimulates saliva production. ${ }^{21}$ This can be useful where some residual gland activity still persists.

\section{Dietary advice}

Patients are encouraged to maintain a normal, balanced diet to ensure adequate nutrition. Dietary advice is ideally given after liaising with a dietician. ${ }^{1}$ Rigid dietary control is impractical, however regular reinforcement of practical dietary advice is likely to be more effective.

While the sensation of taste is absent, it is a good time to give up sugar in tea and coffee and there is less temptation for sweet foods and drinks. However, it is important to maintain such changes when taste sensation returns, when there is often a sudden craving for sweet foods. Dentate patients should be discouraged from attempting to stimulate salivary flow by sucking sweets, but sugar free alternatives can be recommended. ${ }^{22}$

Dysphagia is difficulty with swallowing. Any patient with dysphagia and the inability to take adequate nutrition and hydration by mouth is considered at high nutritional risk. Untreated or poorly managed dysphagia adversely affects quality of life, interferes with cancer treatment and may lead to life threatening conditions, such as aspiration pneumonia. Speech and language therapists will consider the impact and possible consequences of a communication and/or swallowing disorder in patients with head and neck cancer. Speech and language therapist involvement is crucial for planning appropriate swallowing rehabilitation.

As post-treatment symptoms lessen some patients are able to consume more food and drink orally. Dieticians encourage small frequent meals because appetite can be poor at this stage. Subsequently, a high calorie sweet diet may be encouraged for weight maintenance. This needs close surveillance to ensure oral health is not adversely affected. Dysphagia may be a short- and long-term problem and may mean that long-term use of enteral feed or nutritional supplements is required.

Nutritional supplements such as Ensure drinks contain refined carbohydrate (sucrose and/or glucose) and often they are consumed in frequent small sips. This combined with lack of good oral hygiene and poor tolerance or compliance to fluoride toothpastes and mouthwashes inevitably makes this a

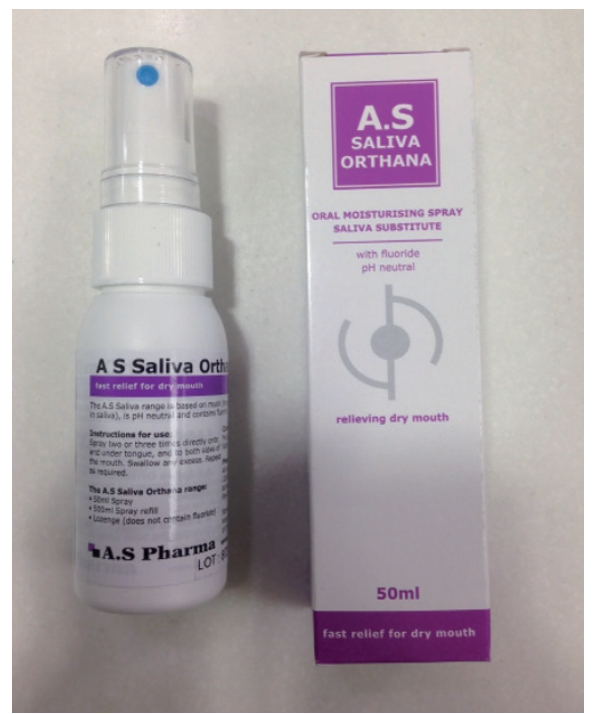

Fig 2a Saliva Orthana ${ }^{\circledR}$

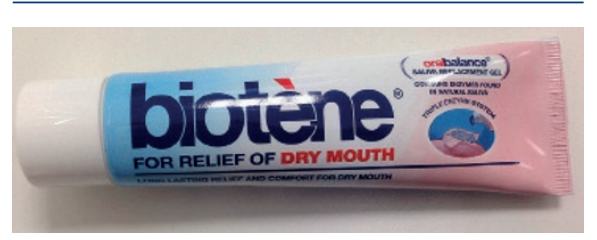

Fig. 2b Biotene Oralbalance ${ }^{\circledR}$

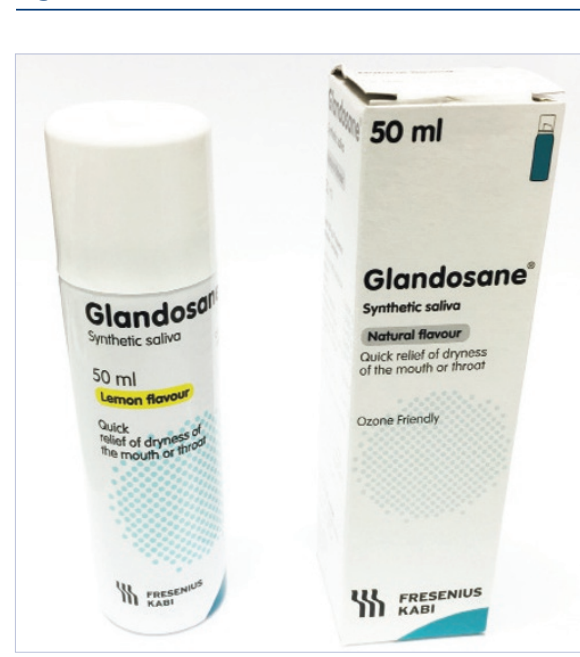

Fig. 2c Glandosane ${ }^{\circledR}$

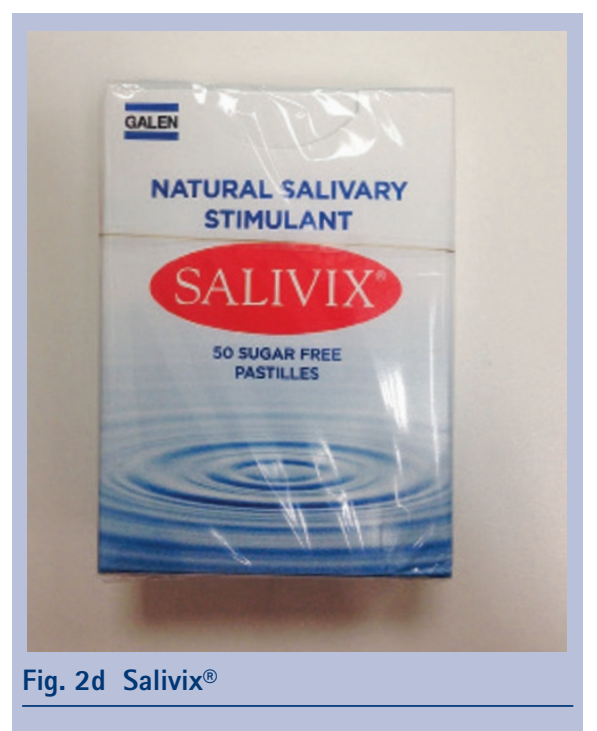




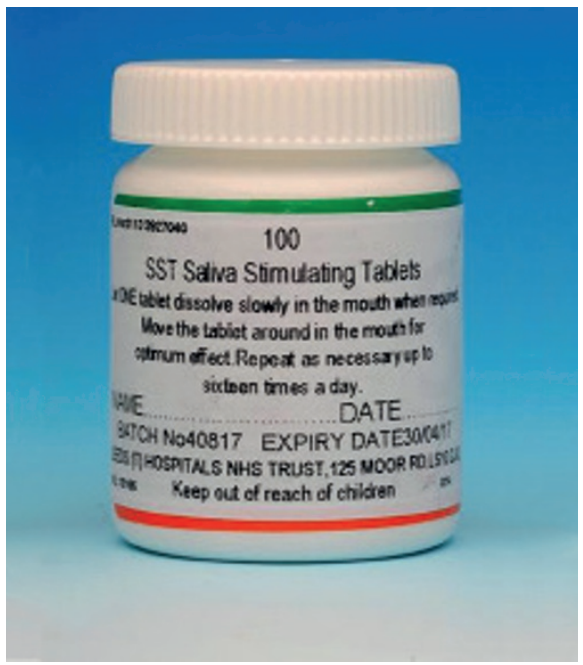

Fig. 2e Saliva stimulating tablets (SST)

high caries risk period. Close liaison with the dietician and dental hygienist at this stage are essential.

\section{Trismus}

Despite better focused radiation dose, progressive jaw stiffness and limitation of opening remains a common complication. ${ }^{23}$ Prevention of trismus, rather than its treatment, is the most desirable objective. ${ }^{24}$

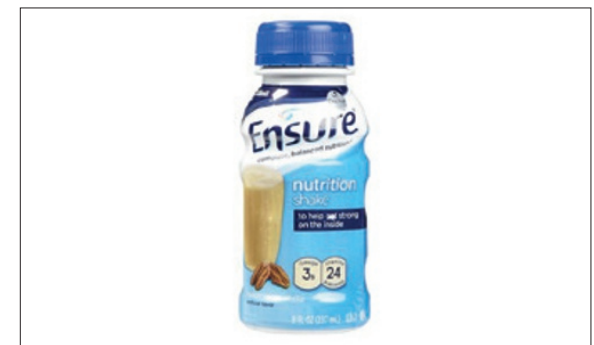

Fig. 3 Nutritional supplements - Ensure ${ }^{\circledR}$ drinks

Patients should be put on home exercises to maintain maximum opening and jaw mobility as soon as radiotherapy begins. ${ }^{25-27}$ Increasing trismus should be investigated for potential local recurrence. ${ }^{28}$ In the event of limitation a strict regimen of mouth exercises is advisable to minimise the problem. A simple wedge made by stacking and taping together tongue spatulas can be used by the patient (Fig. 3), both as a guide to improved opening and as a target for exercises at least three to four times daily. ${ }^{29}$

The TheraBite ${ }^{\circledR}$ jaw motion rehabilitation system is a portable system specifically designed to treat trismus and mandibular hypomobility (Fig. 4). The system uses repetitive passive motion and stretching to

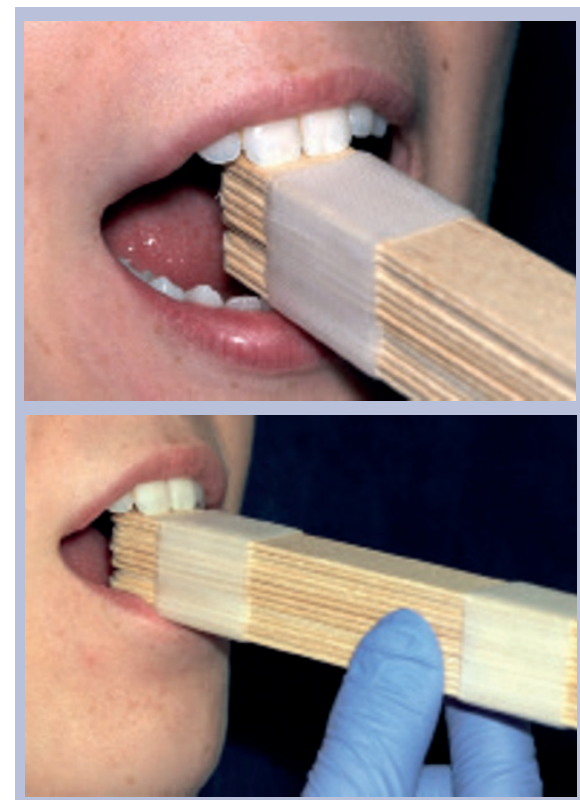

Fig. 4 Wedge constructed from tongue spatulas

restore mobility and flexibility of the jaw musculature, associated joints and connective tissues. ${ }^{28}$ Numerous clinical studies have demonstrated the efficacy of the TheraBite ${ }^{\circledR}$ system. ${ }^{23,30-33}$ TheraBite ${ }^{\circledR}$ apparatus increased

\begin{tabular}{|c|c|c|c|c|}
\hline $\begin{array}{l}\text { Products available } \\
\text { (manufacturer) }\end{array}$ & Formulation & $\begin{array}{l}\text { Prescribe able by dentists } \\
\text { on NHS }\end{array}$ & Fluoride (sodium fluoride) & Animal products \\
\hline Aquoral ${ }^{\circledR+}$ & $\begin{array}{l}\text { Oral spray } 40 \mathrm{ml} \text {, one spray } \\
\text { onto the inside of each cheek } \\
\text { three to four times daily }\end{array}$ & $\begin{array}{l}\text { Yes, may be prescribed as } \\
\text { 'artificial saliva spray' }\end{array}$ & No & No \\
\hline \multirow[t]{2}{*}{ AS Saliva Orthana ${ }^{\circledR+}$ (Fig. 2a) } & $\begin{array}{l}\text { Oral spray } 50 \mathrm{ml} \text {. spray } 2-3 \\
\text { times onto oral and pharyn- } \\
\text { geal mucosa, when required }\end{array}$ & Yes & Yes, $4.2 \mathrm{mg} / \mathrm{l}$ & \multirow[t]{2}{*}{$\begin{array}{l}\text { Yes, contains porcine derived } \\
\text { gastric mucin }\end{array}$} \\
\hline & Lozenges (30) & Yes & No & \\
\hline $\begin{array}{l}\text { Biotene Oralbalance }{ }^{\circledR *} \\
\text { (Fig. 2b) }\end{array}$ & Saliva replacement gel $50 \mathrm{~g}$ & $\begin{array}{l}\text { Yes, may be prescribed as } \\
\text { 'artificial saliva gel' }\end{array}$ & No & $\begin{array}{l}\text { Yes, the manufacturer did not } \\
\text { provide further details as to } \\
\text { what these are }\end{array}$ \\
\hline \multirow{4}{*}{$\begin{array}{l}\text { BioXtra }{ }^{\circledR} \text { products }^{\dagger} \\
\text { The manufacturer advises } \\
\text { avoiding use with tooth- } \\
\text { pastes containing detergents, } \\
\text { including sodium lauryl } \\
\text { sulphate. }\end{array}$} & Moisturising gel $40 \mathrm{ml}$ & Yes & No & \multirow{4}{*}{$\begin{array}{l}\text { Yes, contains animal products } \\
\text { proteins extracted from cow's } \\
\text { milk }\end{array}$} \\
\hline & Gel mouth spray $50 \mathrm{ml}$ & Yes & Yes, 150 ppm & \\
\hline & Toothpaste $50 \mathrm{ml}$ & \multirow[t]{2}{*}{ No } & \multirow[t]{2}{*}{ Yes, 150 ppm } & \\
\hline & Mouthrinse $250 \mathrm{ml}$ & & & \\
\hline Glandosane $^{\circledR *}$ (Fig. 2c) & $\begin{array}{l}\text { Aerosol spray } 50 \mathrm{ml} \text { (lemon, } \\
\text { neutral, peppermint), spray } \\
\text { onto oral and pharyngeal } \\
\text { mucosa as required }\end{array}$ & Yes & No & No \\
\hline Saliveze ${ }^{\circledR \dagger}$ & $\begin{array}{l}\text { Oral spray } 50 \mathrm{ml} \text {, mint- } \\
\text { flavoured, one spray onto oral } \\
\text { mucosa as required }\end{array}$ & Yes & No & No \\
\hline Salivix ${ }^{\circledR *}$ (Fig. 2d) & $\begin{array}{l}\text { Pastilles (50), suck one pastille } \\
\text { when required, sugar free }\end{array}$ & $\begin{array}{l}\text { Yes, may be prescribed as } \\
\text { 'artificial saliva pastilles' }\end{array}$ & No & No \\
\hline $\begin{array}{l}\text { Saliva stimulating tablets* } \\
\text { (Fig. 2e) }\end{array}$ & $\begin{array}{l}\text { Tablets (100), allow one tablet } \\
\text { to dissolve slowly in the mouth } \\
\text { when required }\end{array}$ & Yes & No & No \\
\hline Xerotin $^{\circledR+}$ & Oral spray $100 \mathrm{ml}$ & $\begin{array}{l}\text { Yes, may be prescribed as } \\
\text { 'artificial saliva oral spray' }\end{array}$ & No & No \\
\hline
\end{tabular}


mouth opening significantly more than exercises with wooden tongue spatulas or manual stretching. ${ }^{16}$ A commonly used treatment programme is $7-7-7$, this being seven stretches performed seven times per day, each stretch held for seven seconds. In total, this is an investment of less than ten minutes a day. Individuals who suffer from muscle and/or joint pain may benefit from longer stretch exercises. An example of a treatment programme with longer stretches is 5-5-30, five stretches performed five times per day or more, each stretch held for 30 seconds. ${ }^{28}$

\section{THE ORAL MANAGEMENT OF ONCOLOGY PATIENTS AFTER RADIOTHERAPY}

After radiotherapy has finished, xerostomia is likely to continue to be a problem for the patient, and trismus may become progressively worse. The approaches outlined in the previous section need to be re-emphasised and continued by the patient.

\section{Fluoride and chlorhexidine regimes}

\section{Initial preventive regime}

Tooth brushing should be carried out morning and night with a fluoride-containing toothpaste. The higher fluoridecontaining toothpastes (for example, Durphat, 5,000 ppm) are optimal if patients can tolerate their flavour. Some patients find mint flavoured toothpastes too strong, therefore it is important to recommend alternative product. A sodium fluoride (0.05\%) alcoholfree mouthrinse should be used daily for xerostomic patients to help arrest any initial carious lesions. This will help alleviate sensitivity from pre-existing areas of exposed dentine which have lost the protective action of saliva. ${ }^{34}$ Mouthrinse should be used at a time separate from tooth brushing, such as lunch or tea-time each day. Rinsing should be done for one minute; however the strong flavour may again present as a problem for some patients. The flavours of biotene, oral balance products or children's products are generally better tolerated. OraNurse is unflavoured toothpaste which has $1,450 \mathrm{ppm}$ sodium fluoride (Fig. 5).

\section{Preventive regime when the above is} ineffective

Studies combining the use of fluoride and chlorhexidine have been successful in caries control after radiotherapy. ${ }^{35}$ A $1 \%$ chlorhexidine gel should be applied by the patient in a custom-made applicator tray for five minutes every night for 14 days. This is repeated every three to four months. Such treatment with chlorhexidine has been shown to keep the level of mutans streptococci under control for at least three months. ${ }^{34}$ Several studies have shown that, without dietary restrictions, caries can be successfully controlled by daily self-applications of $1 \%$ sodium fluoride gel in custom-made applicator trays. ${ }^{36-38}$ Fluoride gel should be used every day, with 'breaks', when it is substituted for chlorhexidine gel every three months for a two weeks (as described above). This level of commitment is difficult to achieve for many patients. When patients do not comply fully with such a regime, caries can be uncontrolled, particularly where both parotids have been irradiated. Unfortunately, fluoride gel is now difficult to obtain, as it is no longer marketed or manufactured in UK.

In some cases trismus may exclude the construction or use of fluoride trays. The use of casein phosphopeptide-amorphous calcium phosphate-containing products, such as GC tooth mousse, can prove to be beneficial for remineralising enamel lesions. ${ }^{39}$ Tooth mousse comes in a variety of flavours: strawberry, orange, lemon, vanilla, melon and mint.

\section{Restorative/periodontal treatment}

The effect of radiation on the periodontal tissues makes them more susceptible to disease since the vascularity is reduced and the capacity of the supporting bone to remodel and repair is impaired. Additionally, the reduction of salivary flow encourages the deposition of plaque. Uncontrolled periodontal disease, especially in furcation areas, can predispose to osteoradionecrosis (ORN), making it essential that any evidence of periodontal disease should be treated rigorously. ${ }^{40,41}$ Non-surgical periodontal and restorative treatment can be carried-out as normal.

\section{Extractions}

Dental extractions (or any other surgical intervention involving bone) following radiotherapy, put the patient at risk of ORN and should be avoided if possible. Even soft tissue surgery or trauma can predispose to ORN. If unavoidable they should be undertaken in a hospital environment. Before surgery 0.2\% chlorhexidine gluconate mouthwash should be used. The extractions should be performed carefully with minimal trauma where possible ensuring soft tissue primary closure. Where multiple extractions are required hyperbaric oxygen therapy (HBO) has been recommended both before and after tooth removal. ${ }^{42}$ The significant number of 'dives' involved can, however, lead to poor compliance. The efficacy of HBO for the prevention of ORN is equivocal and is currently being investigated in the UK by a multicentre randomised controlled trial, the hyperbaric oxygen for the prevention of osteoradionecrosis (HOPON) trial.

A systematic review in 2011 on the incidence and prevention of osteoradionecrosis after dental extraction in irradiated patients revealed that the total incidence of ORN is $7 \% .{ }^{43}$ When the extractions were performed in conjuction with prophylatic HBO the incidence was $4 \%$, while extraction in conjuction with antiobiotics gave an incidence of $6 \% .{ }^{43}$

\section{Management of ORN}

Strenuous efforts should be made to avoid osteoradionecrosis by pre-radiotherapy dental assessment. Careful oral health maintenance, timely dental treatment and dealing promptly with oral trauma are all essential in preventing ORN.

When ORN develops, it typically starts as a small area of mucosal breakdown with exposure of the underlying bone. It is often characterised by deep seated bone pain often with a purulent discharge which may include sequestrated bone and may result in significant bone loss. If treated inadequately or left untreated it can be majorly debilitating and

Table 2 Systems of ORN staging

\begin{tabular}{l|l|l|l|l}
\hline Date & Author & Basis of stage & Stages \\
\hline 1983 & Marx ${ }^{45}$ & Response to HBO therapy & I-III \\
\hline 1987 & Epstein et a ${ }^{46}$ & Disease progression & 3 \\
\hline 1995 & Glanzmann and Gratz & $\begin{array}{l}\text { Length of bone exposure and treatment } \\
\text { necessary }\end{array}$ & $1-5$ \\
\hline 2000 & Store and Boysen ${ }^{47}$ & $\begin{array}{l}\text { Combination of radiological and clini- } \\
\text { cal parameters }\end{array}$ & $0-3$ \\
\hline 2002 & Schwartz and Kagan ${ }^{48}$ & Imaging and clinical findings & I-III
\end{tabular}




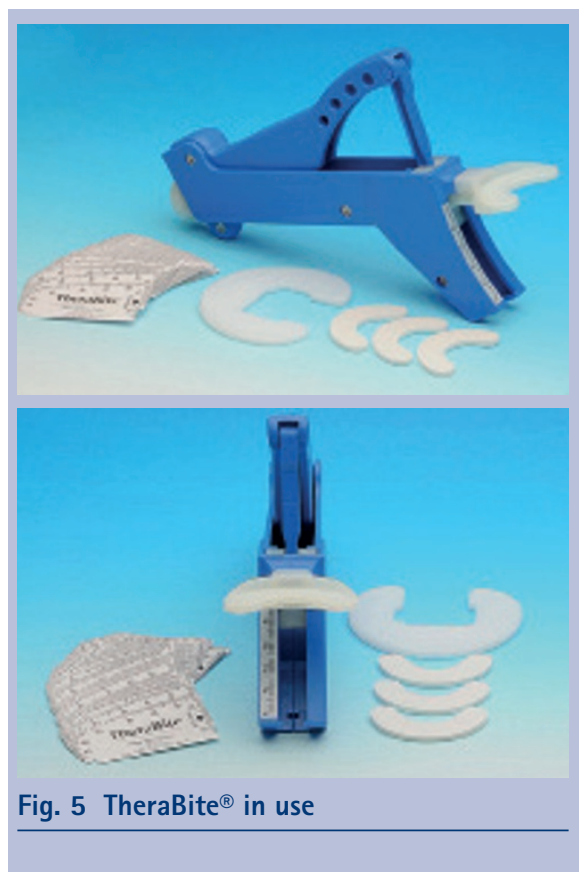

significantly impair quality of life. ${ }^{44}$

There have been several proposed systems of staging ORN (Table 2). Store and Boysen described a three stage clinical staging system of ORN: ${ }^{47}$

- Stage 0: mucosal defects only

- Stage I: radiological evidence of necrotic bone with intact mucosa

- Stage II: positive radiographic findings with denuded bone intraorally

- Stage III: clinically exposed radionecrotic bone, verified by imaging techniques, along with skin fistulas and infection. Radiological evidence of bone necrosis within the radiation field, where tumour recurrence has been excluded.

ORN is a painful and debilitating condition for the patient and can be very difficult to treat. Oral trauma can be reduced by implementation of a soft diet and adjustment or removal of any denture that could be contributing to trauma. Hyperbaric oxygen has been used as an adjunctive treatment modality in the management of ORN since the 1960s. The basis for applying HBO to ORN is an extension of Marx's theory that ORN is the result of tissue hypoxia, hypocellularity and hypovascularity. ${ }^{45}$

The purpose of HBO is to increase the blood-tissue oxygen gradient, which enhances the diffusion of oxygen into hypoxic tissues. The increased oxygen supply stimulates fibroblast proliferation, angiogenesis and collagen formation. ${ }^{45,49}$

HBO therapy (HBOT) involves breathing oxygen under increased atmospheric pressure in a specially designed chamber (Figs 6 and 7). HBOT at 22.5 atmospheres pressure for 1.5-2 hours per day may be

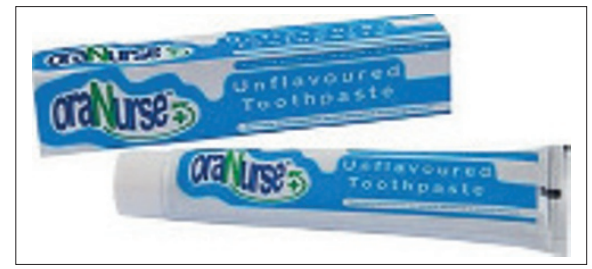

Fig. 6 OraNurse Toothpaste

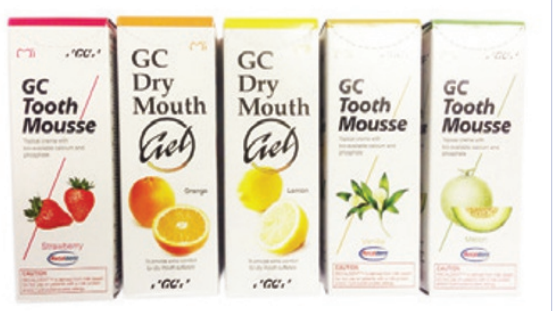

Fig. 7 Tooth Mousse

used. Up to 80 sessions have been recommended to treat severe cases of osteoradionecrosis. ${ }^{50,51}$ Excision of necrosed bone with primary closure and appropriate HBO maybe recommended. Closure of any orocutaneous fistulae will be required. Hemimandibulectomy may be necessary in severe cases with appropriate reconstruction, such surgery being complicated by the irradiated tissues. ${ }^{52,53}$

More recently in the treatment of ORN a synergic effect has been observed between pentoxifylline (PTX) and tocopherol (vitamin E). Antioxidant agent PTX, facilitates microcirculation, and inhibits the inflammatory mechanisms, promotes fibroblast proliferation and the formation of extracellular matrix. Tocopherol protects the cell membrane against peroxidation. These are accessible, well tolerated and safe drugs at a suggested daily dosage of: PTX dose of $800 \mathrm{mg} /$ day and vitamin E 1000 IU/day (five days a week); however more clinical trials are required to validate this treatment. ${ }^{54}$

\section{Dental recall protocols}

The frequency of dental recalls and oral examination depends on an assessment of the patient's risk factors - patients with unstable oral health will require more frequent monitoring. ${ }^{55}$ In circumstances of stable oral health, recall should be agreed with the primary care dentist, with an appropriate procedure for re-referral to a consultant in restorative dentistry if required..$^{56}$ The risk of uncontrolled dental disease after cancer treatment continues indefinitely following radiotherapy, as does the risk of ORN. Without regular reinforcement of preventive regimes and timely care, destruction of

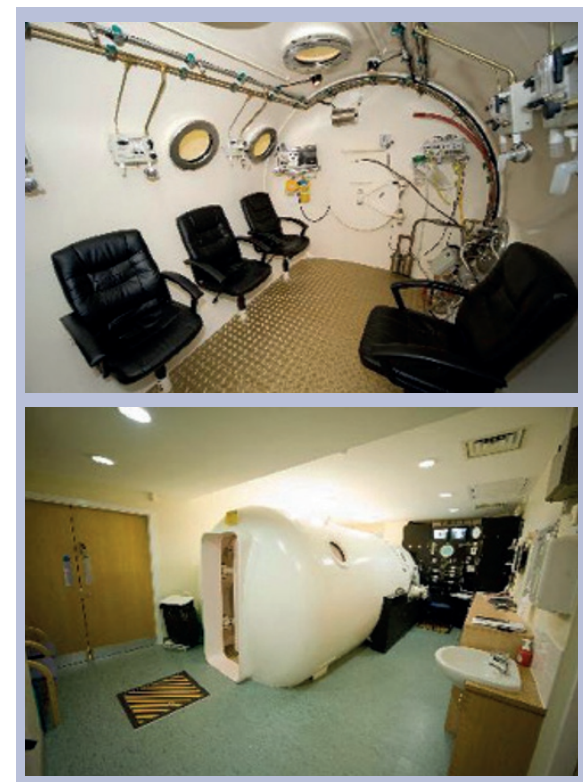

Fig. 8 HBO chamber in Hull

the dentition can be rapid and difficult to control. Thus, regular oral heath monitoring is imperative with three monthly recalls initially until it has been determined that the patient is maintaining their own dentition, then recall can be extended.

\section{The role of the general dental practitioner}

Radiotherapy provides increased survival but has serious adverse consequences which may be lifelong. During radiotherapy the patient will require regular monitoring and support in an effort to decrease the severity of radiotherapy side effects. Oral complications become more severe as the patient progresses through the phase of therapy. Once the acute side effects have resolved, a strict dental hygiene care plan and preventive programme including fluoride treatments must be established. Frequent dental maintenance appointments are imperative not only to check the patient's understanding and compliance of the suggested oral hygiene regime but to also do a thorough extra-oral and intra-oral examination to screen or any new pathology or recurrence.

The GDP has an ongoing role in the tertiary prevention, lifelong vigilance is required and for any patient with a suspicion of recurrence or a new primary malignancy an urgent referral is required.

For those patients who require oral rehabilitation, a consultant with experience in maxillofacial prosthetics and implantology is required. This consultant should manage the oral care and dental treatment for such patients and after treatment is complete should liaise with the GDP to ensure its maintenance 


\section{SUMMARY}

It is essential that a multidisciplinary approach be used for the oral management of head and neck cancer patients. Improving survival rates and an ageing population means that GDPs will see many more survivors of head and neck cancer in the future, with an increased burden of dental care in the longer term and an increased need for monitoring and secondary prevention. The patient's GDP in communication with the restorative consultant on the oncology core team can deliver much of the advice and treatment required. Consequently, it is imperative that GDPs have sound understanding of the oral and dental management of head and neck cancer patients before, during and after radiotherapy.

1. Fayle SA, Duggal M S, Williams SA. Oral problems and the dentists role in the management of paediatric oncology patients. Dent Update 1992; 19: 152-159.

2. Luoma H. Chlorhexidine solutions, gels and varnishes in caries prevention. Proc Finn Dent Soc 1992; 88: 147-153.

3. Ferretti G A, Raybould T P, Brown A T et al. Chlorhexidine prophylaxis for chemotherapyand radiotherapy-induced stomatitis: a randomized double-blind trial. Oral Surg Oral Med Oral Pathol 1990; 69: 331-338.

4. Borowski B, Benhamou E, Pico J L et al. Prevention of oral mucositis in patients treated with high-dose chemotherapy and bone marrow transplantation: a randomised controlled trial comparing two protocols of dental care. Eur J Cancer B Oral Oncol 1994; 30B, 93-97.

5. Foss-Durant A M, McAfee A. A comparison of three oral care products commonly used in practice. Clin Nurs Res 1997; 6: 90-104.

6. 6 Medical Device Alert: Oral swabs with a foam head. MHRA. Ref: MDA/2012/020 Issued: 13 April 2012 at 12:00.

7. Worthington H V, Clarkson J E, Bryan G et al. Interventions for preventing oral mucositis for patients with cancer receiving treatment. Cochrane Database Syst Rev 2011; CD000978.

8. Mahood D J, Dose A M, Loprinzi C L et al. Inhibition of fluorouracil-induced stomatitis by oral cryotherapy. J Clin Oncol 1991; 9: 449-452.

9. Cascinu S, Fedeli A, Fedeli S L, Catalano G. Oral cooling (cryotherapy), an effective treatment for the prevention of 5 fluorouracilinduced stomatitis. Eur J Cancer B Oral Oncol 1994; 30B, 234-236.

10. Epstein J B, Stevenson-Moore P. Benzydamine hydrochloride in prevention and management of pain in oral mucositis associated with radiation therapy. Oral Surg Oral Med Oral Pathol 1986; 62: $145-148$.

11. Scott D B, Julian D G. Oral lignocaine. BMJ 1970; 1 : 297.

12. Cohen M R, Levinsky W J. Topical anaesthesia and swallowing. JAMA 1976; 236: 562

13. Wahlin Y B. Effects of chlorhexidine mouthrinse on oral health in patients with acute leukemia. Oral Surg Oral Med Oral Pathol 1989; 68: 279-287.

14. World Health Organisation. Cancer pain relief 2nd edition. 1996. Geneva, World Health Organisation. Online information available at: http://whqlibdoc. who.int/publications/9241544821.pdf (accessed December 2014)

15. Angirish A. Aspirin-mouthwash relieves pain of oral lesions. J R Soc Health 1996; 116: 105-106.
16. Barkvoll P, Attramadal A. Effect of nystatin and chlorhexidine digluconate on Candida albicans. Ora Surg Oral Med Oral Pathol 1989; 67: 279-281.

17. Clarkson J E, Worthington H V, Eden O B. Interventions for preventing oral candidiasis for patients with cancer receiving treatment. Cochrane Database Syst Rev 2002; 3: CD003807.

18. Worthington H V, Clarkson J E, Khalid T, Meyer S, McCabe M. Interventions for treating oral candidiasis for patients with cancer receiving treatment. Cochrane Database Syst Rev 2007; 18: CD001972.

19. Herod E L. The use of milk as a saliva substitute. $J$ Public Health Dent 1994; 54: 184-189.

20. Walizer E M, Ephraim P M. Double-blind cross-over controlled clinical trial of vegetable oil versus xerolube for xerostomia: an expanded study abstract. ORL Head Neck Nurs 1996; 14: 11-12.

21. Risheim $H$, Arneberg P. Salivary stimulation by chewing gum and lozenges in rheumatic patients with xerostomia. Scand J Dent Res 1993; 101: 40-43.

22. Joyston-Bechal S. Prevention of dental diseases following radiotherapy and chemotherapy. Int Dent J 1992; 42: 47-53.

23. Messing K. Physical exposures in work commonly done by women. Can J Appl Physio/ 2004; 29: 639-656.

24. Goldstein M, Maxymiw W G, Cummings B J, Wood $R E$. The effects of antitumor irradiation on mandibular opening and mobility: a prospective study of 58 patients. Oral Surg Oral Med Oral Pathol Oral Radiol Endod 1999; 88: 365-373.

25. Dreizen S, Daly T E, Drane J B, Brown L R. Oral complications of cancer radiotherapy. Postgrad Med 1977: 61: 85-92.

26. Engelmeier $R L$, King $G$ E. Complications of head and neck radiation therapy and their management. J Prosthet Dent 1983; 49: 514-522.

27. Lockhart P B. Oral complications of radiation therapy. In Peterson D E, Elias E G, Sonis S T (ed) Head and neck management of the cancer patient. pp 429-449. Springer US, 1986.

28. Atos Medical. TheraBite ${ }^{\circledR}$ Catalog. 2009. Online information available at: http://www.atosmedical. com/ /media/Netherlands/TheraBite\%20catalog\%20 7827US.pdf (accessed December 2014).

29. Brunello D L, Mandikos M N. The use of a dynamic opening device in the treatment of radiation induced trismus. Aust Prosthodont J 1995: 9: 45-48.

30. Buchbinder D, Currivan R B, Kaplan A J, Urken M L. Mobilization regimens for the prevention of jaw hypomobility in the radiated patient: a comparison of three techniques. J Oral Maxillofac Surg 1993; 51 : 863-867.

31. Cohen E G, Deschler D G, Walsh K, Hayden R E. Early use of a mechanical stretching device to improve mandibular mobility after composite resection: a pilot study. Arch Phys Med Rehabil 2005; 86: 1416-1419.

32. Dijkstra P U, Kalk W W I, Roodenburg J L N. Trismus in head and neck oncology: a systematic review. Oral Oncol 2004; 40: 879-889.

33. Maloney G E, Mehta N, Forgione A G et al. Effect of a passive jaw motion device on pain and range of motion in TMD patients not responding to flat plane intraoral appliances. Cranio 2002; 20: 55-66.

34. Emilson C G, Bowen W H, Robrish S A, Kemp C W. Effect of the antibacterial agents octenidine and chlorhexidine on the plaque flora in primates. Scand J Dent Res 1981; 89: 384-392.

35. Katz S. The use of fluoride and chlorhexidine for the prevention of radiation caries. J Am Dent Assoc 1982; 104: 164-170.

36. Dreizen S, Brown L R, Daly T E, Drane J B. Prevention of xerostomia-related dental caries in irradiated cancer patients. J Dent Res 1977; 56: 99-104.

37. Johansen $\mathrm{K}$, Asdahl T. [Mass screening and preventive medicine]. Tidsskrift Nor Laegeforen 1979; 99 : 1440-1441.
38. Horiot J C, Bone M C, Ibrahim E, Castro J R. Systematic dental management in head and neck irradiation. Int $J$ Radiat Oncol Biol Phys 1981; 7: 1025-1029.

39. Reynolds E C. Calcium phosphate-based remineralization systems: scientific evidence? Aust Dent J 2008; 53: 268-273.

40. Yusof Z W, Bakri M M. Severe progressive periodontal destruction due to radiation tissue injury. J Periodontol 1993; 64: 1253-1258.

41. Committee on research, science and therapy of the American academy of periodontology. Periodontal considerations in the management of the cancer patient. J Periodontol 1997; 68: 791-801.

42. Makkonen T A, Kiminki A, Makkonen T K, Nordman E. Dental extractions in relation to radiation therapy of 224 patients. Int J Oral Maxillofac Surg 1987; 16: 56-64.

43. Nabil S, Samman N. Incidence and prevention of osteoradionecrosis after dental extraction in irradiated patients: a systematic review. Int J Oral Maxillofac Surg 2011; 40: 229-243.

44. Silvestre-Rangil J, Silvestre F J. Clinico-therapeutic management of osteoradionecrosis: a literature review and update. Med Oral Patol Oral Cir Bucal 2011; 16: e900-904.

45. Marx R E. Osteoradionecrosis: a new concept of its pathophysiology. J Oral Maxillofac Surg 1983; 41: 283-288.

46. Epstein J B, Wong F L, Stevenson-Moore P. Osteoradionecrosis: clinical experience and a proposal for classification. J Oral Maxillofac Surg 1987. 45: 104-110

47. Store G, Boysen M. Mandibular osteoradionecrosis: clinical behaviour and diagnostic aspects. Clin Otolaryngol Allied Sci 2000; 25: 378-384.

48. Schwartz H C, Kagan A R. Osteoradionecrosis of the mandible: scientific basis for clinical staging. Am J Clin Oncol 2002; 25: 168-171.

49. Marx R E, Johnson R P. Studies in the radiobiology of osteoradionecrosis and their clinical significance. Oral Surg Oral Med Oral Pathol 1987; 64: 379-390.

50. Lambert P M, Intriere N, Eichstaedt R. Clinical controversies in oral and maxillofacial surgery: Part one. Management of dental extractions in irradiated jaws: a protocol with hyperbaric oxygen therapy. J Oral Maxillofac Surg 1997; 55: 268-274.

51. London S D, Park S S, Gampper T J, Hoard M A. Hyperbaric oxygen for the management of radionecrosis of bone and cartilage. Laryngoscope 1998; 108: 1291-1296.

52. Yanagiya K, Takato T, Akagawa T, Harii K Reconstruction of large defects that include the mandible with scapular osteocutaneous and forearm flaps: report of cases. J Oral Maxillofac Surg 1993: 51: 439-444.

53. Serletti J M, Coniglio J U, Tavin E, Bakamjian VY. Simultaneous transfer of free fibula and radial forearm flaps for complex oromandibular reconstruction. J Reconstr Miscrosurg 1998; 14: 297-303.

54. Delanian S, Chatel C, Porcher R, Depondt J, Lefaix $\mathrm{J}$ L. Complete restoration of refractory mandibular osteoradionecrosis by prolonged treatment with pentoxifyllinetocopherolclodronate combination (PENTOCLO): a phase II trial. Int J Radiat Oncol Biol Phys 2011: 80: 832-839.

55. National Institute for Health and Care Excellence. Dental recall: full guideline. 2004, revised 2014. Online information available at: http://www.nice.org. uk/guidance/CG19 (accessed December 2014).

56. Royal College of Surgeons of England. The oral management of oncology oncology patients requiring radiotherapy, chemotherapy and/or bone marrow transplantation. 2012. Online information available at : http://www.rcseng.ac.uk/fds/publicationsclinical-guidelines/clinical_guidelines/documents/ clinical-guidelines-for-the-oral-management-ofoncology-patients-requiring-radiotherapy-chemotherapy-and-or-bone-marrow-transplantation (accessed December 2014). 